\title{
MANAGEMENT OF CONGENITAL NEUROLOGICAL DEFECTS: ANAESTHESIOLOGIST'S CHALLENGE
}

\author{
Harpreet Kaur1, Ranjana², Veena Chatrath ${ }^{3}$ \\ ${ }^{1}$ Associate Professor, Department of Anaesthesia and Critical Care, Government Medical College, Amritsar. \\ ${ }^{2}$ Associate Professor, Department of Anaesthesia and Critical Care, Government Medical College, Amritsar. \\ 3Professor, Department of Anaesthesia and Critical Care, Government Medical College, Amritsar.
}

\begin{abstract}
Lumbosacral meningomyelocele and hydrocephalus are two major congenital neurological defects in paediatric patients.

\section{METHODS}

We have discussed management of two cases, one of large meningomyelocele and second of massive hydrocephalus. Both cases were done successfully under general anaesthesia taking care of proper positioning. Child with meningomyelocele was positioned supine on two sand bags, creating a doughnut shaped depression to accommodate the meningomyelocele. Patient with hydrocephalus was placed on $25 \mathrm{cms}$ high pillow with head on a high head ring and an assistant's hand supporting the head while intubation.
\end{abstract}

\section{RESULTS}

Major challenges for anaesthesiologist in these patients include airway management with proper positioning, replacement of blood and fluid losses and maintenance of body temperature.

\section{KEYWORDS}

Airway Management, Body Temperature, Hydrocephalus, Meningomyelocele, Patient Positioning.

HOW TO CITE THIS ARTICLE: Kaur H, Ranjana, Chatrath V. Management of congenital neurological defects: anaesthesiologist's challenge. J. Evolution Med. Dent. Sci. 2016;5(22):1203-1205, DOI: 10.14260/jemds/2016/279

\section{INTRODUCTION}

Lumbosacral meningomyelocele and hydrocephalus are two major congenital neurological defects in paediatric patients.

Meningomyelocele (MMC) is a complex congenital spinal anomaly resulting from neural tube defect during first 4 weeks of gestation. Incidence is 0.4 to 1 out of 1000 live births, but incidence varies with environmental and genetic factors. ${ }^{1,2,3}$ Failure of closure of neural tube in embryo result in sac like herniation of neural elements and meninges. Most common site is Lumbosacral. ${ }^{4}$ but it can occur at any level in the neuroaxis. Spinal cord is often tethered caudally by sacral roots, resulting in orthopaedic and urological symptoms during childhood if not corrected. ${ }^{4}$ Varying degrees of motor and sensory deficits in the form of flaccid paraplegia, loss of anal, urethral and bladder sphincter tone are present. Associated congenital conditions include hydrocephalus $(67.4 \%) .{ }^{5}$ club foot, intestinal malformations, renal anomalies, cardiac malformations and tracheoesophageal fistula. ${ }^{1}$ Hydrocephalus (HC) is an enlargement of ventricles by increased Cerebrospinal Fluid (CSF) secretion or decreased drainage either by obstruction to CSF pathways or by decreased absorption by arachnoid villi. It may be due to congenital or acquired causes, out of which $55 \%$ cases have congenital origin. ${ }^{6}$ It leads to increase in the head circumference. It can present with multiple challenges including undiagnosed genetic anomalies and prematurity associated comorbidities. Distortion of normal airway by

Financial or Other, Competing Interest: None.

Submission 03-02-2016, Peer Review 29-02-2016,

Acceptance 05-03-2016, Published 17-03-2016.

Corresponding Author:

Dr. Harpreet Kaur,

Mohindra House, 12,

Albert Road,

Rani Ka Bagh,

Amritsar.

E-mail: rupihar@gmail.com

DOI: $10.14260 /$ jemds $/ 2016 / 279$ macrocephaly leads to difficult airway management in patients of significant hydrocephalus. Brainstem compression may be caused by extension of head during intubation. ${ }^{1}$

Here, we present management of 2 cases - one of large lumbosacral meningomyelocele and other of massive hydrocephalus.

\section{Case I}

One and a half year old female child weighing 11 kilograms $(\mathrm{kg})$ with a large meningomyelocele in lumbosacral region was posted for excision. This was accompanied by deformity in both feet and weakness in both legs. No history of tuberculosis, convulsions, drug allergy was present. In the birth history, the child was delivered by lower segment caesarean section with APGAR score of 8 in the $1^{\text {st }}$ minute and birth weight of $2.5 \mathrm{~kg}$.

On examination, child was crying and moving both upper limbs. There was a large swelling of about $20 \times 25 \mathrm{~cm}$ lumbosacral region. There was a history of gradual increase in size of swelling since birth till present size. Overlying skin was thin, shiny and intact. Glasgow coma score was 15/15. Power was $2 / 6$ in both lower limbs. Muscle tone and reflexes were decreased bilaterally. There was accompanying talipes equinovarus in both feet. $S_{1}$ and $S_{2}$ were normal with no murmur.

Breath sounds were normal with no added sounds. Haematocrit, platelet count, coagulation profile, renal function tests and serum electrolytes were normal. Patient was kept nil orally for 4 hours prior to surgery. She was wheeled in operation theatre in lateral position. Percentage of oxygen saturation $\left(\mathrm{SPO}_{2}\right)$, Electrocardiogram (ECG), precordial stethoscope and temperature probes were attached. Warm Ringer Lactate (RL) was started on already placed 22G intravenous (IV) cannula. Premedication was given using Injection atropine $20 \mu \mathrm{g} / \mathrm{kg}$ and Injection fentanyl $2 \mu \mathrm{g} / \mathrm{kg}$.

Two sand bags, about $25 \mathrm{~cm}$ high were places on operating table (OT) and child was placed on sand bags in supine position with one sand bag below the shoulders and 
other below the buttocks. A doughnut shaped depression was created to accommodate the meningomyelocele so as to avoid any pressure on it. A high head ring was placed below the head. Body was covered with cotton pads.

Anaesthesia was induced with Injection thiopentone $2.5 \% 50 \mathrm{mg}$ IV slow. After confirming mask ventilation, patient was given Injection atracurium $5 \mathrm{mg}$ IV and intubated using non cuffed Endotracheal Tube (ET) no. 4.0mm. Proper precautions were taken to avoid hanging of the head. An assistant supported the head of the child with his hand while intubation. Bilateral air entry was checked and tube secured. Anaesthesia was maintained with $50 \% \quad \mathrm{O}_{2}+50 \% \quad \mathrm{~N}_{2} \mathrm{O}$ and sevoflurane. Eyes were padded to prevent pressure. Patient put in prone position by placing rolls below chest and hips to make abdomen free for ventilation. Bilateral air entry was rechecked. Both extremities were padded and draped to prevent hypothermia. Intraoperatively vital monitoring- $\mathrm{SPO}_{2}$, ECG, precordial stethoscopy, temperature and End Tidal Carbon Dioxide $\left(\mathrm{EtCO}_{2}\right)$ were continued; $120 \mathrm{~mL}$ of $\mathrm{RL}$ was infused and $100 \mathrm{~mL}$ of blood was transfused intraoperatively to replace the losses. On completion of surgery, neuromuscular blockade was reversed using Injection neostigmine $0.5 \mathrm{mg}$ IV and Injection atropine $0.2 \mathrm{mg}$ IV. After thorough oropharyngeal suctioning, child was extubated when fully awake with regular respiration.

\section{Case II}

A 3-year-old male child (Weight-14kg) presented with a very large head and was posted for Ventricular Peritoneal (VP) Shunt removal due to shunt infection. Child had a history of lethargy, poor feeding, vomiting and convulsions since one day. History of VP shunt insertion, three months back under General Anaesthesia (GA) was there. Child was born through Lower Segment Caesarean Section (LSCS) with a birth weight of $2 \mathrm{~kg}$ and head size of $45 \mathrm{~cm}$. He was put on IV antibiotics and syrup phenytoin 6 hours prior to surgery.

On examination the child was lethargic, moving limbs sluggishly. Head was massively enlarged with circumference of $90 \mathrm{~cm}$. Anterior fontanelle was wide and bulging. Eyes of child were bulging and looking downwards (Sunset sign positive). Respiratory System and Cardiovascular System (CVS) were normal. Investigations like haematocrit, total leucocyte count, platelet count, coagulation profile were normal. CSF study showed neurophilia, increased protein content and decreased sugar. After wheeling the child into operation theatre, warm RL was started on a pre-positioned $22 \mathrm{G} I V$ cannula. Injection atropine $20 \mu \mathrm{g} / \mathrm{kg}$ was used for premedication. Injection fentanyl $2 \mu \mathrm{g} / \mathrm{kg}$ was given for analgesia and to attenuate the stress response of intubation. Child was positioned on a $25 \mathrm{~cm}$ high pillow, placed on the OT table. The child's head was placed on a large and soft head ring. Body of child was covered with large cotton pads. Anaesthesia was induced with Injection thiopentone $2.5 \% 75 \mathrm{mg}$ IV. After checking for mask ventilation, child was intubated with ET no. $4.5 \mathrm{~mm}$ ID after giving Injection atracurium $6 \mathrm{mg}$ iv. After checking for bilateral air entry tube was secured. Anaesthesia was maintained using $50 \% \mathrm{O}_{2}+50 \% \mathrm{~N}_{2} \mathrm{O}$ with sevoflurane. $\mathrm{SPO}_{2}, \mathrm{EtCO}_{2}$, ECG, precordial stethoscopy and temperature were monitored; $150 \mathrm{~mL}$ of RL was infused intraoperatively.

After completion of surgery and adequate oropharyngeal suction, neuromuscular blockade was reversed with Injection neostigmine $1 \mathrm{mg}$ IV and Injection atropine $0.3 \mathrm{mg}$ IV. Child was extubated when fully awake.

\section{DISCUSSION}

Recent advances in neurosurgery, neuromonitoring and neurointensive care have dramatically improved the outcome of patients affected by surgical lesions of Central Nervous System (CNS). Paediatric patients present a set of inherent challenges because of their developing and maturing neurological and physiological status apart from CNS disease process. ${ }^{7}$ Major challenges for anaesthesiologist in congenital neurological defects in paediatric patients include:

- Securing airway with proper positioning.

- Replacement of blood loss in case of large MMC and fluid and electrolyte loss in case of hydrocephalus.

- Maintenance of body temperature due to large area of exposed tissue and cold preparation solutions used during surgery.

\section{Positioning and Airway Protection}

Majority of MMC defects occur in lumbosacral area and neurological deficits distal to defect are more severe. To avoid rupture of the swelling, positioning is very important. Induction and intubation should be done in lateral position or supine position by putting the placode within a padding made in shape of a doughnut to avoid its rupture. ${ }^{4}$ One case reports intubating MMC case by lifting the child in air by two assistants. ${ }^{8}$ For surgical repair, child has to be made prone. Abdomen should be kept free by placing chest and hip rolls to facilitate ventilation, decrease intra-abdominal pressure and decrease bleeding from epidural plexus. ${ }^{5}$ Excessive neck rotation should be avoided due to possibility of Arnold Chiari Malformation (ACM); $20 \%$ of MMC infants with ACM have vocal cord weakness due to lower cranial nerve palsies leading to inspiratory stridor, apnea due to central hypoventilation, swallowing dysfunction, bradycardia, nystagmus, torticollis, upper limb weakness and spasticity. ${ }^{1}$

In children with hydrocephalus, macrocephaly may distort normal anatomy of skull, making airway management difficult. Large occiput places neck in extreme flexion and large forehead may obscure the line of sight of laryngoscopy. So elevating the body with pillows or towels or placing pillow below the shoulders is necessary in order to facilitate laryngoscopy. ${ }^{4}$ It is not advisable to hang the head over the edge of the table as stability is poor.

There may be a considerable blood loss during repair of large MMC when large amount of skin is to be undermined to cover the defect. Cases of hypotension not responding to blood or fluid replacement have been reported, which may be due to sudden loss of CSF from sack leading to brain herniation. ${ }^{1}$ Hydrocephalus patient may require fluid replacement due to emesis or drug induced diuresis.

Hypothermia is frequent considering the surface area of tissue exposed (MMC), large head (HC), age of the patient and use of cold solutions during surgery. Also autonomic control below the level of MMC is abnormal. ${ }^{8}$ Hypothermic neonates are prone to apnea, bradycardia, hypotension and acidosis. In addition, it leads to prolonged recovery from neuromuscular block, impairs platelet functions and lead to more incidence of wound infection. 5

It can be prevented by use of overhead warmers in OT, use of warm infusion fluids, covering the child with cotton 
pads or drapes and use of warming mattresses and hot air warming blanket such as Bair hugger device. ${ }^{5}$

Children with hydrocephalus are prone to hypertension and bradycardia (Cushing's response). ${ }^{6}$ Intracranial hypertension can be prevented by avoiding hypoxia and hypercapnia, as it causes cerebral vasodilatation and may worsen raised intracranial pressure especially in combination with laryngoscopy and airway manipulation. 6 Treating hypotension, hyperventilation, elevating the head end of the bed and avoiding Positive End Expiratory Pressure (PEEP) are advisable to prevent venous congestion. ${ }^{9}$

We conclude that congenital neurological defects in paediatric patients are major challenges for the anaesthesiologists requiring careful planning and meticulous approach for patient safety.

\section{REFERENCES}

1. Chand MB, Agrawal J, Bista P. Anaesthetic challenges and management of myelomeningocele repair. Postgrad Med J nams 2011;11:41-6.

2. Arts MP, Jong de TH. Thoracic meningocele, meningomyelocele or myelocystocele? diagnostic difficulties, consequent implications and treatment. Paediatr neurosurg 2004;40:75-79.
3. Adzick NS. Foetal myelomeningocele: natural history, pathophysiology and in-utero intervention. Semin Fetal Neonatal Med 2010;15:9-14.

4. Singh D, Rath GP, Dash HH, et al. Anaesthetic concerns and perioperative complications in repair of myelomeningocele: a retrospective review of 135 cases. J Neurosurg Anaesthesiol 2010;22:11-5.

5. Soundararajan N, Cunliffe M. Anaesthesia for spinal surgery in children. Br J Anaesthes 2007;99:86-94.

6. Garg R, Sokhal N, Rath G. Anaesthetic consideration of a child with concomitant craniovertebral junction anomaly and arrested hydrocephalus. Acta Anaesthesiol Belg 2015;66:33-6.

7. Rath GP, Dash HH. Anaesthesia for neurosurgical procedures in paediatric patients. Indian J Anaesth 2012;56:502-10.

8. Ravishankar RB, Kavya KG, Jnaneshwar CS. Intubation in air!-an innovative method for meningomyelocele excision surgery: a case report. Journal of evidence based medicine health care 2014;1:184-9.

9. Malinzak EB, Taicher BM. Anaesthetic considerations for congenital hydrocephalus. Paediatric Anaesthesia and Critical Care Journal 2015;3:10-4. 